\title{
Comparative Evaluation of Flexural Strength Among Cad-Cam Milled and Resin Provisional Restoration- an in Vitro Study
}

\author{
Gayathri Karthikeyan ${ }^{1}$, Ashok V², Kiran Kumar ${ }^{3}$ and Dhanraj Ganapathy ${ }^{4}$ \\ ${ }^{1}$ Department of Prosthodontics Saveetha Dental College and Hospitals Saveetha \\ Institute of Medical and Technical Sciences, Saveetha University, Chennai, India \\ ${ }^{2}$ Professor and Head (Admin), Department of Prosthodontics Saveetha Dental College and \\ Hospitals Saveetha Institute of Medical and Technical Sciences, Saveetha University Chennai, India \\ ${ }^{3}$ Senior Lecturer Department of Prosthodontics, Saveetha Dental College and Hospitals \\ Saveetha Institute of Medical and Technical Sciences, Saveetha University Chennai, India \\ ${ }^{4}$ Professor and Head (Academics), Department of Prosthodontics, Saveetha Dental College and Hospitals \\ Saveetha Institute of Medical and Technical Sciences, Saveetha University Chennai, India
}

\section{ABSTRACT}

The aim of the study was to compare the flexural strength among cad-cam milled and heat cured provisional restoration. Fixed Partial Denture (FDP) plays an important part in fixed prosthodontic treatment. Provisional restorations must satisfy biologic, esthetic, and mechanical requirements There is not a single material or method that has been found to be useful in all clinical situations, so it is important to know the properties of the material in order to know the limitations and indications/contraindications for their clinical use for extended periods of time. A total of 16 specimens are used for the study. The specimens are divided into two groups , the CAD-CAM provisional and the Conventional Heat polymerized resin provisional. The specimens are tested using Universal Testing Machine (INSTRON ELECTROPULS E3000) and a three-point loading system is used for the application of load and all the 16 specimens are subjected to the three-point bending test. Results are tabulated and one-way ANOVA analysis performed. It is noted that the highest force that is exerted on a CAD-CAM milled provisional is $358.42 \mathrm{MgPa}$ and flexural strength for that force is 65.22 , highest force that is exerted on heat cured provisional is $160.33 \mathrm{MgPa}$ and flexural strength for that force is 30.89. A one-way ANOVA test is done and the association is found to be statistically significant with a p-value of $0.001(<0.05)$ for both, proving that there is a significant difference in the flexural strength between the CAD-CAM provisional restoration and heat cured provisional restoration. It can be concluded that there is a significant difference in the flexural strength between the CAD-CAM provisional restoration and heat cured provisional restoration and CAD -CAM resin group specimens exhibited higher flexural strength values followed by heat cured resin group

KEY WORDS: CAD-CAM, HEAT CURE, APICAL PROVISIONAL, RESIN, FLEXURAL STRENGTH.

\section{ARTICLE INFORMATION}

*Corresponding Author: gayathri.1913@gmail.com

Received 30th July 2020 Accepted after revision 23rd Sep 2020

Print ISSN: 0974-6455 Online ISSN: 2321-4007 CODEN: BBRCBA

Thomson Reuters ISI Web of Science Clarivate Analytics USA and Crossref Indexed Journal

$$
\begin{aligned}
& \text { Clarivate } \\
& \text { Analytics }
\end{aligned}
$$




\section{INTRODUCTION}

Provisional Fixed Partial Dentures (FDP) plays an important part in fixed prosthodontic treatment. Provisional restorations must satisfy biologic, esthetic, and mechanical requirements such as resistance to functional loads, resistance to removal forces, and maintenance of abutment alignment (Land and Fujimoto, 1995). There is not a single material or method that has been found to be useful in all clinical scenarios, so it is important to know the properties of the material in order to know the limitations, indications/contraindications for their clinical use for extended periods of time.(Gratton and Aquilino, 2004). The majority of materials that can be used for the fabrication of provisionals can be broadly divided into two main components: (a) Methyl methacrylate resins and (b) composite resins . Traditional methyl methacrylate type resins are mono-functional low molecular weight, linear molecules that exhibit decreased strength and rigidity whereas composite resins are difunctional and capable of cross-linking with another monomer chain imparting strength and toughness to the material (Haselton, Diaz-Arnold and Vargas, 2002).

Computer-Aided Designing and Computer-Aided Manufacturing(CAD-CAM) was first used in dentistry in the 1970s. CAD-CAM (CC) has now become a wellaccepted technology in most modern dental laboratories and for some enterprising clinicians at the chair-side (van Noort, 2012).

Heat polymerized acrylic resin is stronger, has greater stability, and is more resistant to polymer breakdown than auto polymerized resin. It also has the advantages of color stability, maintenance of surface finish, and resistance to wear (Binkley and Thomas Irvin, 1987). Provisional restorations fabricated from heat-processed acrylic resin can function satisfactorily for extended periods of time (Madhav, Digholkar and Palaskar, 2016). Previously our department has published extensive research on various aspects of prosthetic dentistry ('Evaluation of Corrosive Behavior of Four Nickel-chromium Alloys in Artificial Saliva by Cyclic Polarization Test:An in vitro Study', 2017; Ganapathy, Kannan and Venugopalan, 2017; Jain, 2017a, 2017b; Ranganathan, Ganapathy and Jain, 2017; Ariga et al., 2018; Gupta, Ariga and Deogade, 2018; Anbu et al., 2019; Ashok and Ganapathy, 2019; Duraisamy et al., 2019; Varghese, Ramesh and Veeraiyan, 2019), this vast research experience has inspired us to research about the Comparison of flexural strength among cad-cam milled and heat cured provisional restoration. The aim of this study is to evaluate the flexural strength among heat polymerized resin provisional and the CAD CAM resin provisional restoration.

\section{MATERIAL AND METHODS}

A total of 16 specimens are used for the study. The specimens are divided into two groups, the CAD-CAM provisional restoration and the Conventional Heat polymerized resin provisional restoration.

\section{Preparation of Specimens}

Conventional heat polymerized resin specimens: To fabricate the exact size and shape of the specimens, the bridge designing is done using the CAD (3-shape software) technology. Then for the fabrication of heat polymerized resin the design is converted into pattern resin using CAM technology. These pattern resin specimens are invested in conventional flasks and the heat polymerized PMMA specimens are fabricated using the compression molding technique (Fig 1).

Figure 1: Heat polymerized resin provisional restoration

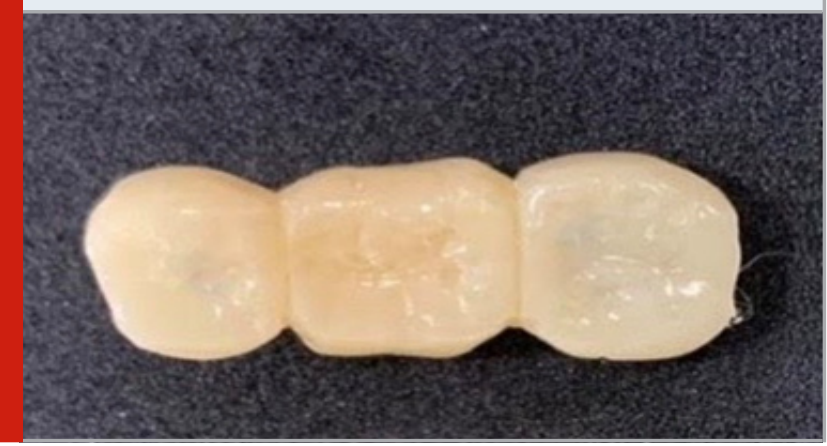

CAD-CAM provisional specimens: The bridge design done for the fabrication of heat polymerized resin is used for the milling of CAD-CAM provisionals. The design is transferred to a milling machine( mesi-icore, Germany) containing the PMMA banks that mill the CAD CAM provisional restoration (Fig 2).

Figure 2: CAD-CAM milled resin provisional restoration

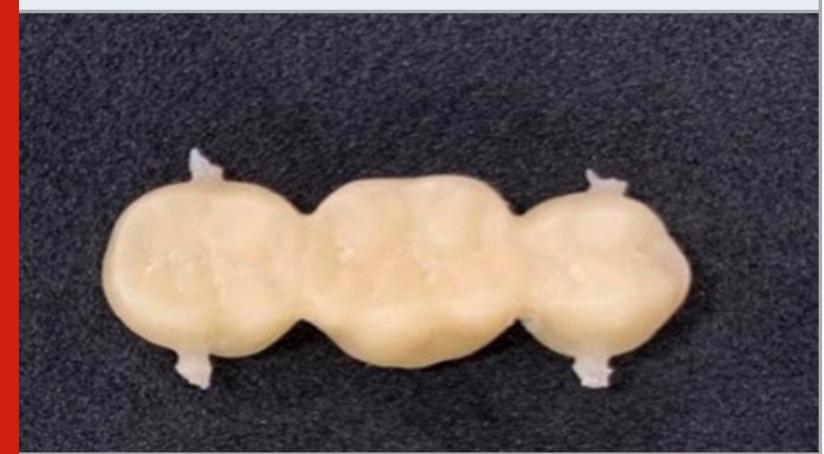

Figure 3: Application of load using Universal Testing Machine

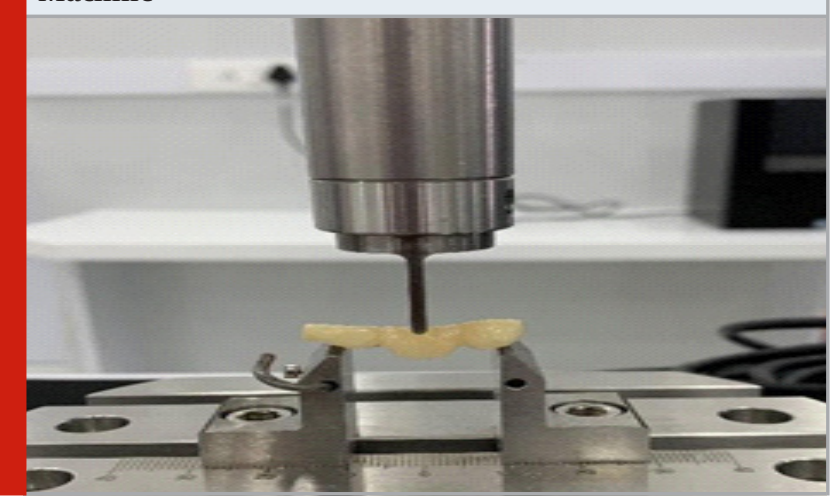




\section{Testing of Specimens}

Flexural strength determination: A Universal Testing Machine (INSTRON ELECTROPULS E3000) is utilized for this study and a three-point loading system is used for the application of load and all the 16 specimens of the two groups are subjected to the three-point bending test (fig 3). The loading is continued till fracture occurred and the breaking load is noted. These breaking load values are converted to flexural strength. The flexural strength values are recorded in MegaPascals (MPa) by the software provided by the machine.

Statistical analysis: The flexural strength is recorded for each specimen. This raw data of the values obtained are tabulated in excel following the tabulation the data is imported into spss and a one way ANOVA test is carried out to compare the values.

\section{RESULT AND DISCUSSION}

The highest force that is exerted on a CAD-CAM milled provisional is $358.42 \mathrm{MgPa}$ and flexural strength for that force is 65.22, highest force that is exerted on heat cured provisional is $160.33 \mathrm{MgPa}$ and flexural strength for that force is 30.89. A one-way ANOVA test is done and the association is found to be statistically significant with a p-value of $0.001(<0.05)$, proving that there is a significant difference in the flexural strength between the CAD-CAM provisional restoration and heat cured provisional restoration.

Provisional fixed dental prostheses (FDPs) are an integral part of fixed prosthodontics and dental implantology. The provisional FDPs must satisfy the requirements of pulpal protection, periodontal health, occlusal compatibility, maintaining tooth position, protection against fracture, resistance to functional loads, resistance to removal forces, maintaining inter-abutment alignment, be easily contourable, color stable, and have sufficient translucency (Madhav, Digholkar and Palaskar, 2016). The prognosis of a fixed restoration depends on the quality of this interim restoration (Kachhara et al., no date).

Conventionally, various methods and materials have been introduced to provide a provisional restoration that is esthetic, easy to fabricate, most importantly having a high strength and hardness. These materials for the fabrication of single and multiple unit provisional restorations are mostly resin based. They differ with regard to the method of polymerization, filler composition, and monomer type (Donaldson, 2012).

If the provisional FDPs are expected to function for extended periods of time or when additional therapy is required before completion of definitive treatment viz. during the prosthetic phase of dental implants and reconstructive procedures, while evaluation of a change in vertical dimension, for orthodontic stabilization, in case of assessing the results of periodontal and endodontic therapies and in cases of bruxism, the improved mechanical properties play an important role
(Binkley and Thomas Irvin, 1987) (Sen, Göller and Issever, 2002) (Hamza et al., 2006).

A study reviewed CAD-CAM systems used in dentistry and proposed its use for provisionalization. Manufacturing under industrial conditions permits high-density polymer-based restorations which offer favourable mechanical behaviour and biocompatibility (Rekow, 2006). These CAD-CAM restorations also reduce the chair side time of the patient (Güth et al., 2012) Thus CAD-CAM approach is becoming more popular for the fabrication of tooth-colored indirect restorations (Rocca et al., 2010). In the study conducted by Shruti et al CAD - CAM resin group specimens exhibited highest flexural strength values followed by heat cured resin group which is consistent with this study.

Graph 1: shows the comparison of the flexural strength of the types provisional restorations at the maximum forces (X-axis represents the flexural strength at maximum force, Y-axis represents the maximum force exerted) where blue represents the CAD-CAM milled provisionals and green represents heat cured provisionals. It was noted that the highest force that was exerted on a CADCAM milled provisional was $358.42 \mathrm{MgPa}$ and flexural strength for that force was 65.22, highest force that was exerted on heat cured provisional was $160.33 \mathrm{MgPa}$ and flexural strength for that force was 30.89. A one-way ANOVA test was done and the association was found to be statistically significant with a p-value of $0.001(<0.05)$ for both, proving that there is a significant difference in the flexural strength between the CAD-CAM provisional restoration and heat cured provisional restoration.

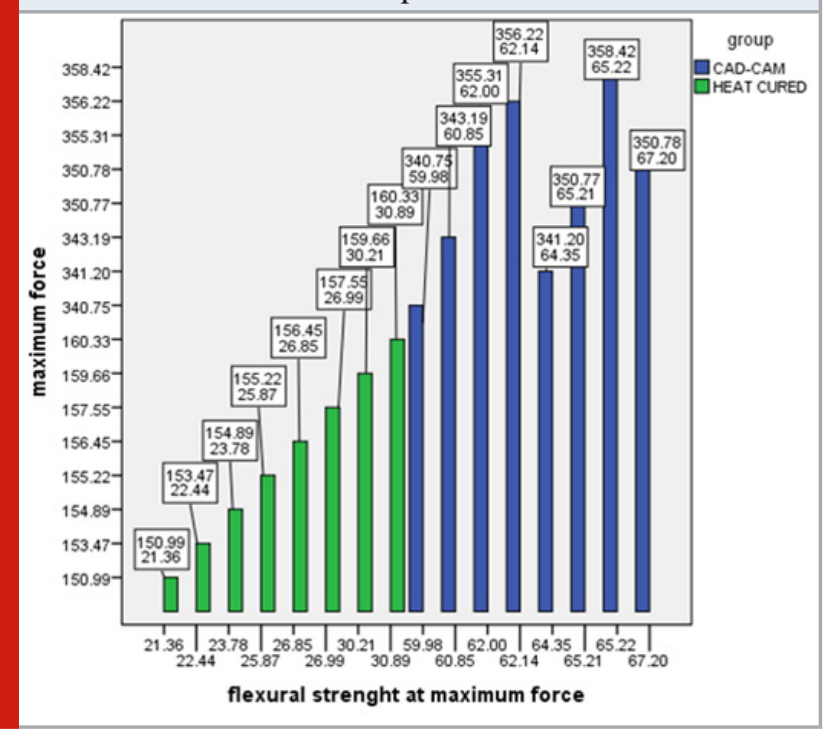

According to a study concluded by Edelhoff et al the high-density polymers based on highly cross-linked resins are manufactured in an industrial process, thus, exhibiting superior qualities in case of the CAD-CAM acrylic resin blanks (Edelhoff et al., 2012). These findings are similar to the research conducted by Alt et al. who investigated the influence of fabrication method, storage condition, and use of different materials, on the fracture 
strength of provisional 3-unit FDPs using CC technologies and resin-based blanks cured under optimal conditions (Alt et al., 2011). The conventional heat activated specimens are made by the same operator according to the manufacturers' instructions, but the samples are prepared at different time intervals. Therefore, operator related variations and absence of cross-linking in the conventional heat activated resin could have led to lesser flexural strength values in these specimens when compared to the CAD-CAM resin specimens (Yanikoglu et al., 2014). Moreover, the improved fit of the milled $\mathrm{CAD} / \mathrm{CAM}$ provisional lowers the risk of bacterial contamination of the tooth and prevents damage to the pulp from excessive temperature changes (Karaokutan, Sayin and Kara, 2015) (Renne et al., 2015).

\section{CONCLUSION}

Within the limitations of this in vitro study, and on the basis of the results obtained, it can be concluded that CAD -CAM resin group specimens exhibited higher flexural strength values compared by heat cured resin group. Since the CAD-CAM milled Provisionals exhibited greater flexural strength it can be used in cases where Provisionals have to be worn for a long period of time as it won't fracture under the load. CAD- CAM milled Provisionals also have lesser chair side time fabrication

Conflict of Interest: The author would like to declare there was no conflict of interest

\section{ACKNOWLEDGEMENTS}

I would like to thank my esteemed institution for providing me with the opportunity to do this study and would also like to thank my guide for her expert advice and encouragement which helped me with the completion of this study.

\section{REFERENCES}

Alt, V. et al. (2011) 'Fracture strength of temporary fixed partial dentures: CAD/CAM versus directly fabricated restorations', Dental materials: official publication of the Academy of Dental Materials, 27(4), pp. 339-347. Anbu, R. T. et al. (2019) 'Comparison of the Efficacy of Three Different Bone Regeneration Materials: An Animal Study', European journal of dentistry, 13(1), pp. 22-28.

Ariga, P. et al. (2018) 'Determination of Correlation of Width of Maxillary Anterior Teeth using Extraoral and Intraoral Factors in Indian Population: A Systematic Review', World Journal of Dentistry, 9(1), pp. 68-75. Ashok, V. and Ganapathy, D. (2019) 'A geometrical method to classify face forms', Journal of oral biology and craniofacial research, 9(3), pp. 232-235.

Binkley, C. J. and Thomas Irvin, P. (1987) 'Reinforced heat-processed acrylic resin provisional restorations', The Journal of Prosthetic Dentistry, pp. 689-693. doi:

\subsection{6/0022-3913(87)90364-7.}

Donaldson, K. J. (2012) 'Fundamentals of fixed prosthodontics, fourth edition', British Dental Journal, pp. 427-427. doi: 10.1038/sj.bdj.2012.978.

Duraisamy, R. et al. (2019) 'Compatibility of Nonoriginal Abutments With Implants: Evaluation of Microgap at the Implant-Abutment Interface, With Original and Nonoriginal Abutments', Implant dentistry, 28(3), pp. 289-295.

Edelhoff, D. et al. (2012) 'CAD/CAM-generated highdensity polymer restorations for the pretreatment of complex cases: a case report', Quintessence international . researchgate.net, 43(6), pp. 457-467.

Evaluation of Corrosive Behavior of Four Nickelchromium Alloys in Artificial Saliva by Cyclic Polarization Test:An in vitro Study' (2017) World Journal of Dentistry, 8(6), pp. 477-482.

Ganapathy, D. M., Kannan, A. and Venugopalan, S. (2017) 'Effect of Coated Surfaces influencing Screw Loosening in Implants: A Systematic Review and Meta-analysis', World Journal of Dentistry, 8(6), pp. 496-502.

Gratton, D. G. and Aquilino, S. A. (2004) 'Interim restorations', Dental clinics of North America. europepmc.org, 48(2), pp. vii, 487-97.

Gupta, P., Ariga, P. and Deogade, S. C. (2018) 'Effect of Monopoly-coating Agent on the Surface Roughness of a Tissue Conditioner Subjected to Cleansing and Disinfection: A Contact Profilometric Study', Contemporary clinical dentistry, 9(Suppl 1), pp. S122S126.

Güth, J. F. et al. (2012) 'Enhancing the predictability of complex rehabilitation with a removable CAD/CAMfabricated long-term provisional prosthesis: a clinical report', The Journal of prosthetic dentistry. Elsevier, 107(1), pp. 1-6.

Hamza, T. A. et al. (2006) 'Fracture resistance of fiberreinforced PMMA interim fixed partial dentures', Journal of prosthodontics: official journal of the American College of Prosthodontists, 15(4), pp. 223-228.

Haselton, D. R., Diaz-Arnold, A. M. and Vargas, M. A. (2002) 'Flexural strength of provisional crown and fixed partial denture resins', The Journal of prosthetic dentistry, 87(2), pp. 225-228.

Jain, A. R. (2017a) 'Clinical and Functional Outcomes of Implant Prostheses in Fibula Free Flaps', World Journal of Dentistry, 8(3), pp. 171-176.

Jain, A. R. (2017b) 'Prevalence of Partial Edentulousness and Treatment needs in Rural Population of South India', World Journal of Dentistry, 8(3), pp. 213-217. Kachhara, S. et al. (no date) Effect of various polishing agents on the color stability of provisional crowns. Available at: https://bit.ly/32VTGBi 
Karaokutan, I., Sayin, G. and Kara, 0. (2015) 'In vitro study of fracture strength of provisional crown materials', The journal of advanced prosthodontics, 7(1), pp. 27-31.

Land, M. F. and Fujimoto, J. (1995) Contemporary Fixed Prosthodontics. Mosby.

Madhav, V. N. V., Digholkar, S. and Palaskar, J. (2016) 'Evaluation of the flexural strength and microhardness of provisional crown and bridge materials fabricated by different methods', The Journal of Indian Prosthodontic Society, p. 328. doi: 10.4103/0972-4052.191288.

van Noort, R. (2012) 'The future of dental devices is digital', Dental materials: official publication of the Academy of Dental Materials. Elsevier, 28(1), pp. 3-12.

Ranganathan, H., Ganapathy, D. M. and Jain, A. R. (2017) 'Cervical and Incisal Marginal Discrepancy in Ceramic Laminate Veneering Materials: A SEM Analysis', Contemporary clinical dentistry, 8(2), pp. 272-278.

Rekow, E. D. (2006) 'Dental CAD/CAM systems: a 20year success story', Journal of the American Dental Association , 137 Suppl, p. 5S-6S.
Renne, W. et al. (2015) 'Evaluation of the Marginal Fit of CAD/CAM Crowns Fabricated Using Two Different Chairside CAD/CAM Systems on Preparations of Varying Quality', Journal of esthetic and restorative dentistry: official publication of the American Academy of Esthetic Dentistry ... [et al.], 27(4), pp. 194-202.

Rocca, G. T. et al. (2010) 'A technique to improve the esthetic aspects of CAD/CAM composite resin restorations', The Journal of prosthetic dentistry, 104(4), pp. 273-275.

Sen, D., Göller, G. and Issever, H. (2002) 'The effect of two polishing pastes on the surface roughness of bisacryl composite and methacrylate-based resins', The Journal of prosthetic dentistry, 88(5), pp. 527-532.

Varghese, S. S., Ramesh, A. and Veeraiyan, D. N. (2019) 'Blended Module-Based Teaching in Biostatistics and Research Methodology: A Retrospective Study with Postgraduate Dental Students', Journal of dental education, 83(4), pp. 445-450.

Yanikoglu, N. D. et al. (2014) 'Flexural Strength of Temporary Restorative Materials Stored in Different Solutions', Open Journal of Stomatology, pp. 291-298. doi: 10.4236/ojst.2014.46041. 